\title{
A cenografia como espectáculo
}

\section{lan Herbert}

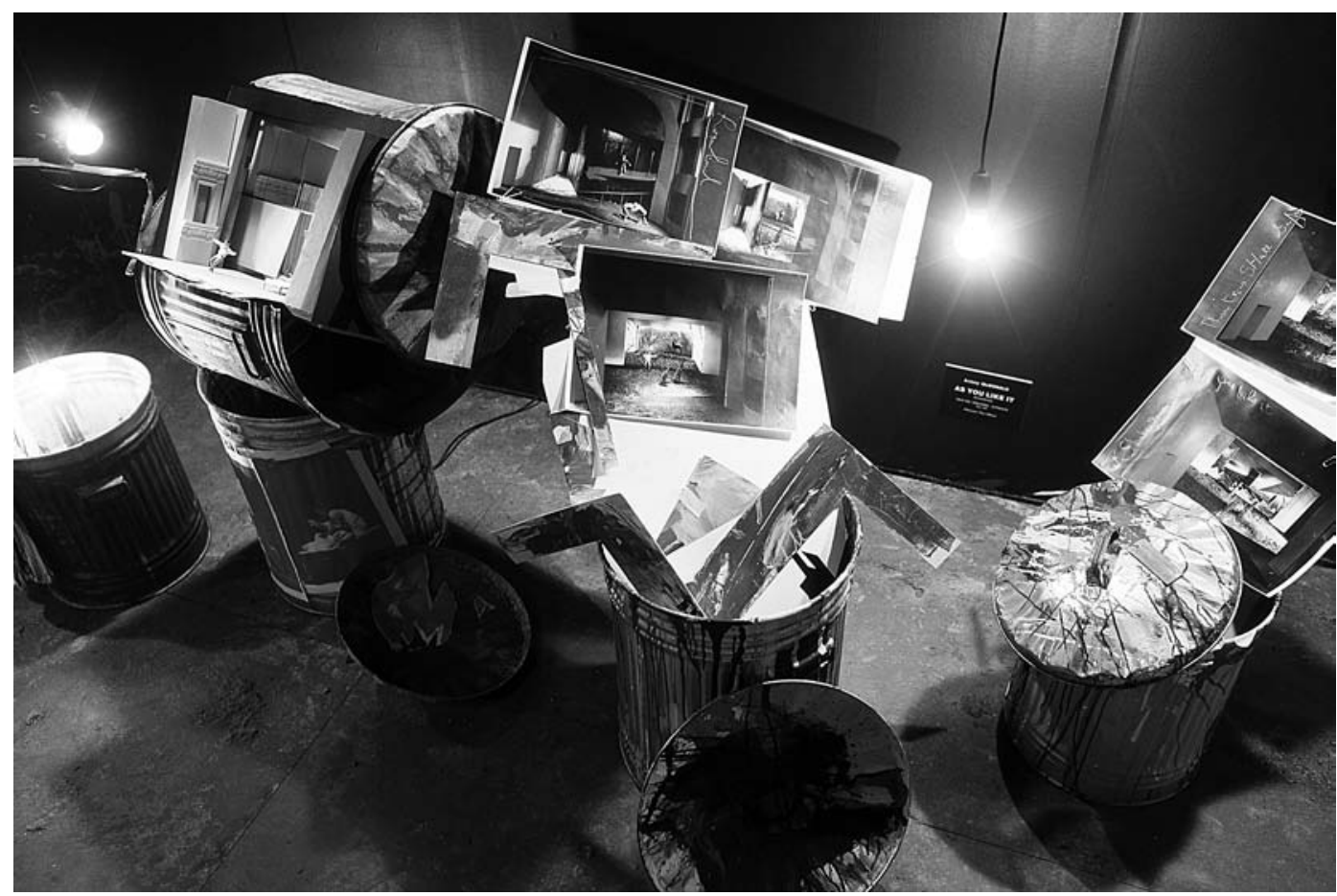

Pavilhão britânico, com o trabalho dos artistas da Escola de Balls Pond Road, incluindo Richard Hudson e Nigel Lowery, Quadrienal de Praga 2007, fot. Viktor Kronbauer.

A recente Quadrienal de Praga, dedicada à cenografia e à arquitectura teatral, apresenta-se como um pretexto oportuno para examinar o papel da cenografia e dos cenógrafos no teatro actual. As cerca de cinquenta representações nacionais que integraram a exposição da Quadrienal, bem como as mostras dos inúmeros estudantes que participaram, seguiram, pelo menos, três abordagens distintas: aquelas que tentaram dar uma perspectiva abrangente do trabalho realizado, nos últimos quatro anos, pelos criadores e pelas escolas de um determinado pais; aquelas que preferiram concentrar-se num único cenógrafo ou personalidade do meio teatral; e ainda aqueles pavilhões que eram, eles próprios, a obra exposta. (Numa quarta categoria, que irei ignorar, a representação nacional dos Países Baixos e das escolas britânicas evitaram completamente qualquer tipo de apresentação, optando antes pela realização de discussões e demonstrações sobre o tema da cenografia.)

A tarefa de representar toda a produção de um pais é intimidante. Ainda assim, foram os Estados Unidos, talvez com a cena teatral mais vasta e variada do mundo, que encararam este desafio com mais seriedade, dando igual proeminência ao trabalho da Broadway, ao teatro regional e ao circuito universitário. A Grã-Bretanha tinha, numa escala muito mais reduzida, uma variedade semelhante, embora a sua opção tenha recaído numa selecção de diferentes cenógrafos britânicos, cujos trabalhos haviam sido antes apresentados numa exposição de âmbito nacional. Entre os países que também optaram por esta abordagem contam-se o México (cujos figurinistas venceram a medalha de ouro), a Espanha e a Tailândia, com exposições particularmente bem construidas que se mostraram à altura do desafio.

Em cada um destes casos, a ênfase colocou-se no trabalho feito. Outros paises, como Hong Kong, o Japão ou a Nova Zelândia, tornaram o modo de apresentação tão relevante como o material apresentado, com o Japão expondo belos cenários num sushibar, Hong Kong atolando trabalhos igualmente bons num comentário muito dispendioso acerca do consumismo, e a Nova Zelândia a quase esconder os esforços dos seus cenógrafos numa disposição inteligente mas, de certa forma, impenetrável, que obrigava os visitantes a enfiar a cabeça dentro de uma série de cones de plástico.

Aqueles paises que preferiram concentrar-se num único cenógrafo tiveram mais facilidade em afirmar-se, como se demonstrou através do impacto inegável da montagem portuguesa da obra de João Mendes Ribeiro (que acabaria por vencer a medalha de ouro para cenografia), da elegante apresentação de Boris Kudlicka, da Eslováquia, e da exposição de Monika Pormale, da Letónia (cenógrafa de Alvis Hermanis). Ainda assim, lan Herbert

Editor durante largos anos da revista britânica Theatre Record, lan Herbert é o actual Presidente da Associação Internacional de Críticos de Teatro. 


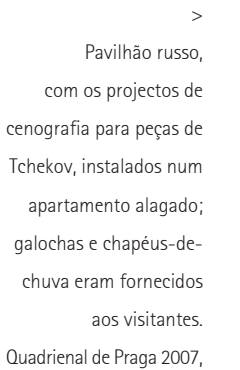

Quadriena de Praga 2007.

fot. Martina Novozamska.
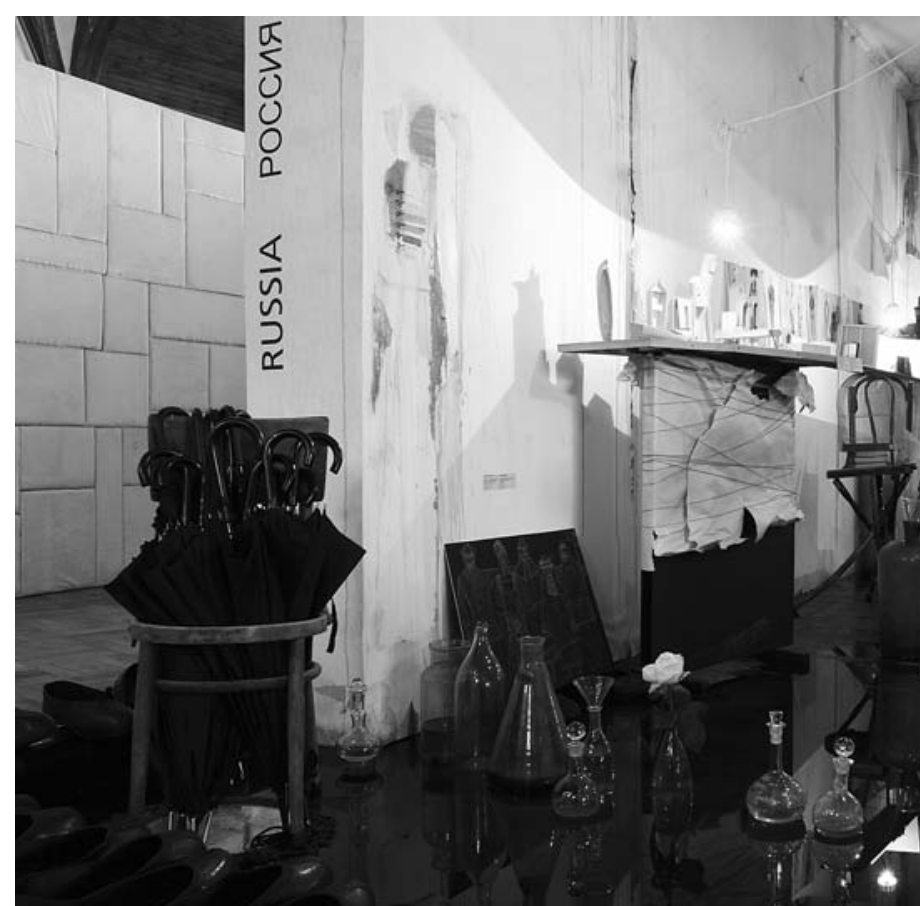
o 


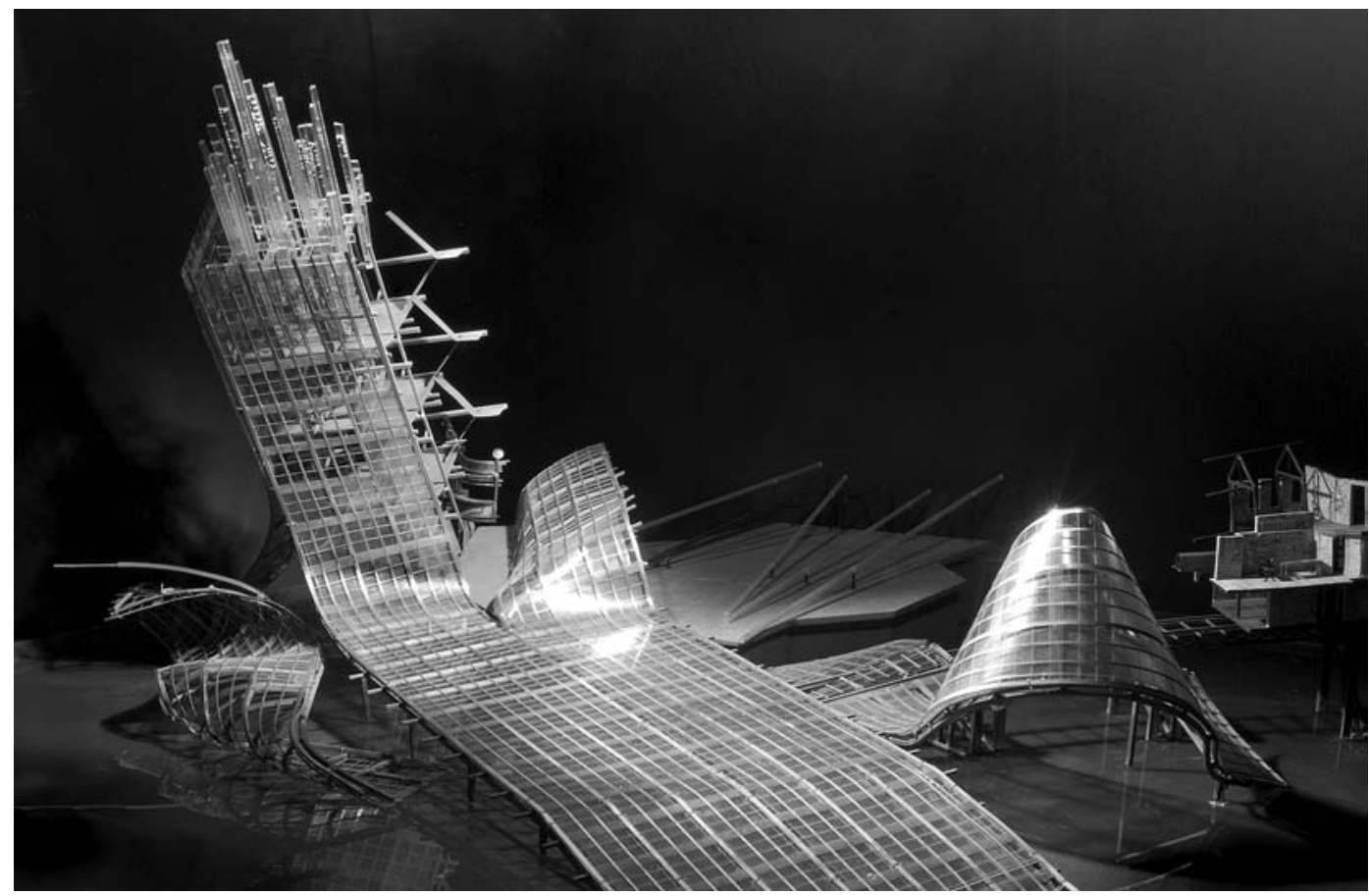

particularmente na ópera, ameaçava dominar completamente todo o espectáculo: é fácil admirar o gigantismo cenográfico do palco do festival de Bregenz, na margem do lago homónimo, onde se apresentaram alguns dos mais maravilhosos cenários integrados em encenações operáticas talvez menos satisfatórias; já será menos fácil aplaudir algum dos trabalhos da escola britânica de Balls Pond Road - também distinguida com um prémio nesta Quadrienal -, cujos magníficos cenários tantas vezes ofuscaram o desempenho de cantores e maestros nas grandes salas de ópera do mundo. Parece assistir-se, no domínio da cenografia para ópera, a um retorno, cada vez mais vincado, a um maior equilibrio, em consequência não só de constrangimentos económicos, mas também de novas orientações artísticas por parte das colaborações entre cenógrafos e encenadores.

Recordo-me, há alguns anos atrás, de estar a discutir cenografia com Timothy O'Brien, um dos mais reputados cenógrafos britânicos, ele próprio distinguido numa anterior edição da Quadrienal de Praga. Dizia ele que sempre que os seus projectos surgiam mencionados em críticas de teatro ou de ópera, ele sentia que tinha falhado.

Apresentava-se como um crente sincero na função auxiliar da cenografia: qualquer cenografia que sobressaisse, pensava ele, era má, uma vez que teria interferido com o propósito central do espectáculo, que era comunicar directamente com o espectador.

Embora esta seja uma perspectiva extrema e purista, ela resume, basicamente, a atitude do cenógrafo-artesão. Não será uma perspectiva partilhada pelo cenógrafoartista: Tadeusz Kantor, em especial, tinha o hábito, nas suas criações mais tardias, de permanecer no palco com os seus actores: embora a finalidade fosse encorajá-los, o resultado era a presença do "maestro" no centro do palco, a par dos seus cenários e dos seus actores-intérpretes. Os cenógrafos-artistas, beneficiando da nossa aceitação do modernismo e da sua alegria face ao abstracto, têm conseguido apresentar obras em cena que se mostram dificeis ou mesmo impossiveis de compreender, sob quaisquer modos de interpretação aristotélicos, mas que causaram o seu impacto enquanto simples obras de arte. Esta abordagem ao teatro, excitante mas perigosa, permitiu que muitos charlatães sem nada para dizer tivessem a oportunidade de criar sensações e de atrair alguns seguidores devotos, ao abrigo do sagrado nome da abstracção. Falando pessoalmente, mantenho uma considerável dose de cepticismo em relação ao trabalho de vários cenógrafos-artistas de renome, entre os quais (e apenas para provocar alguns dos meus colegas) destacaria Jan Fabre como o maior charlatão de entre todos.

Fabre é seguido, algo a meio caminho, por Robert Wilson, sem dúvida um brilhante cenógrafo-artista, cujas imagens são, invariavelmente, a parte mais relevante do seu trabalho. (Também gostaria de destacá-lo, como um dos grandes desenhadores de luz do nosso tempo.) Wilson é citado no espectáculo a solo Bob, interpretado por Will Bonds e encenado por Ann Bogart - curiosamente, apresentado na Quadrienal de Praga deste ano - como tendo dito: "Os artistas raramente compreendem o que estão a fazer". Ele preferia que fosse o público - e talvez em particular os críticos, enquanto membros mais qualificados do público - a retirar as suas próprias conclusões acerca daquilo que o artista estava a tentar dizer ou fazer.

E aqui encontramos o grande paradoxo que tenho tentado abordar, com as minhas palavras acerca dos cenógrafos-artistas: a grande arte pode produzir os seus efeitos sem qualquer necessidade de participação intelectual por parte do espectador - revelando-se, simplesmente. Contudo, quaisquer imitadores pretensiosos poderão macaquear essa grande arte, apresentando-se como obscuros, misteriosos, sem qualquer mensagem imediata - quando, de facto, não têm nenhuma mensagem nem história para contar.

Terão já percebido que a minha preferência recai sobre a figura do cenógrafo-artesão. Desejo um teatro que me estimule a todos os niveis possiveis - cabeça, coração, 
0 desconcertante interio op-art do pavilhão sérvio Quadrienal de Praga 2007, fot. Martina Novozamsk
Pavilhão japonês com balcão de sush e exposição de maquetas

e fotografias de espectáculos,

Quadrienal de Praga 2007, fot. Martina Novozamska.
${ }^{2} 0$ autor refere-se à versão inglesa do texto do próprio João Mendes Ribeiro, "Arquitecturas em

palco", destinado ao catálogo da exposição homónima apresentada no âmbito da Quadrienal de

Praga 2007. N.T. visceras, até da alma - e o trabalho que terá mais hipóteses de alcançar isto, a meu ver, será aquele em que toda a equipa, integrada pelo encenador, o cenógrafo, o figurinista, o dramaturgo e os actores, tenha trabalhado em conjunto. Haverá ocasiões em que um único criador me deslumbra profundamente; todavia, esses serão momentos mais raros do que aqueles em que são os esforços colectivos de um conjunto de talentos que causam o seu impacto.

Finalmente, para voltar à asserção de Robert Wilson de que os artistas raramente compreendem o que estão a fazer, aqui está um excerto da descrição de um outro artista acerca do seu próprio trabalho, publicado no catálogo da Quadrienal de Praga:

A linha conceptual que preside à selecção dos diversos projectos e intervenções reflecte o espirito contemporâneo de hibridação e experimentalismo, as questões da efemeridade e transformação, o cruzamento de matérias ou conhecimentos provenientes de diversas áreas. Pretende-se expor a apetência relacional dos espaços cénicos num amplo contexto de referências que se estende do
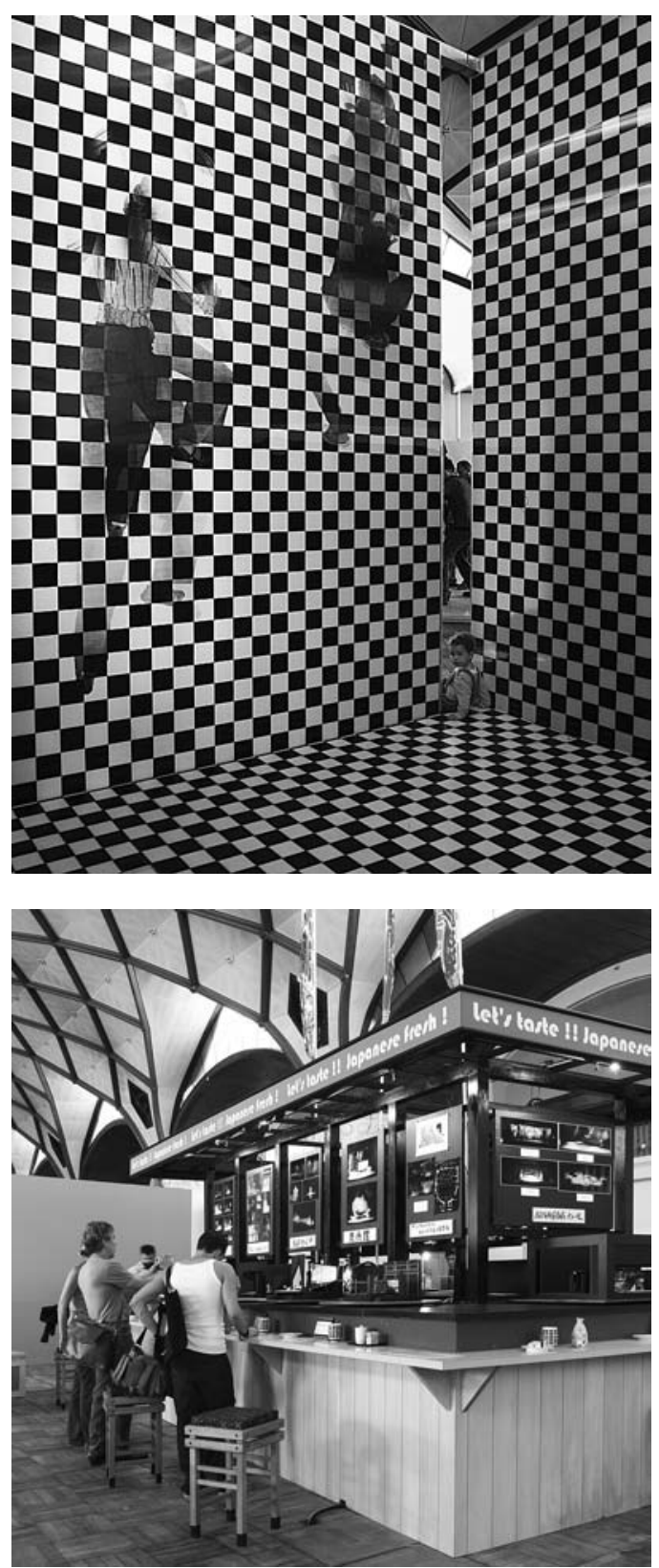

universo significante da encenação, do ritual e do simbólico, a valores outros, virtualmente abstractos, como os de um certo funcionalismo racionalista. Nos diferentes projectos, exploramse as relações entre corpo e espaço - escala, gestualidade e materialidade - no contexto das práticas artísticas e arquitectónicas contemporâneas, reflectindo o tema da percepção e os processos de representação e comunicação. Por meio de uma linguagem essencial, austera e depurada, não muito distante da prática da arte minimal e do expressionismo abstracto, as intervenções em causa enfatizam um certo subjectivismo, onde as propriedade físicas do espaço, escala e materiais, são exploradas como fenómenos autónomos, nas suas intrínsecas qualidades plásticas.

Quem lesse estas palavras talvez decidisse passar

rapidamente ao largo da exposição. Caso o tivesse feito, teria perdido o trabalho soberbo de João Mendes Ribeiro, que venceu a Medalha de Ouro da Quadrienal de Praga para Cenografia.

Tradução de Marta Costa Dias 